\title{
SESSION 3 OVERVIEW: MANAGEMENT OF ASTRONOMICAL PECULARITIES
}

Carol Hutchins

Swain Hall Library

Indiana University

Bloomington, IN 47405

USA

Session 3 on "Handling and Use of Special Format Materials" dealt with diverse items which are of unique importance in astronomical libraries.

Preprints and reprints are important in several ways. Libraries' collection and dissemination of information about pre-publication journal and conference papers boosts the astronomer's awareness of current research in a timely fashion. Individual libraries' practices range from very basic--the receipt and physical display of preprints--to the more elaborate activities including production of lists, gathering of subsequent publication information about the papers themselves, construction of local databases listing preprints, and electronic network exchange of listings.

There was a consensus that the sending of reprint series is far less important than it was in years past.

We heard a call for formal recognition or designation of a central clearinghouse for information about astronomy preprints.

Some parts of the world (China, for example) are not receiving preprints, or information about them, on a regular basis. Reprints themselves may still be considered valuable for retention by some small institutes in eastern Europe which do not have many journal subscriptions.

Observatory publication series are considered indispensible in astronomy collections. They are sometimes accorded special shelving locations. These series present many bibliographic problems and may be variously arranged by geography or by classification number, or otherwise.

It was emphasized by one speaker (Anne Fishburn) that the use of observatory publications is difficult to assess. Libraries must take them seriously, but at the same time exercise pragmatism in managing them. A concern was raised about the need for a central clearinghouse for duplicates of these serials.

Non-print material has always been an important feature in our astronomy libraries. Microfiche has been appropriate for distribution of certain data, such as small catalogs or material ancillary to journal papers. It seems that magnetic tapes are not ubiquitous in our libraries. Magnetic and optical media were not commented upon extensively. Still, there is a great interest in the problems of catalogs or listings of magnetic tapes and also the management of documentation for these tapes. Special environment and handling must be accorded tapes just to maintain readability of the data.

Special physical storage and handling is likewise essential to the preservation of unique collections of visual information contained in sky surveys in their print, film, or glass copies.

Management of the peculiar items found in astronomy libraries poses challenges to us on a daily basis. Creative solutions will continue to arise and be improved via sharing of ideas, and perhaps through joint efforts in some cases. 